\title{
Analysis of Learning Effect of Engineering Courses in Higher Vocational Colleges of Engineering
}

\author{
Miao Shang ${ }^{1, a^{*}}$, Xiaoli Wang ${ }^{1, b}$ and Jinwen Zhao ${ }^{1, c}$ \\ ${ }^{1}$ Department of electromechanical technology, Xijing University, Xi'an, China

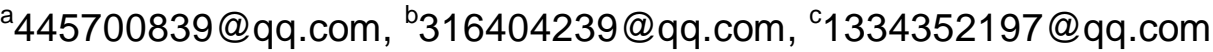 \\ *The Corresponding author
}

\begin{abstract}
Keywords: Higher education; Curriculum settings; Assessment mode; Talent cultivation; Project teaching
\end{abstract}

\begin{abstract}
The talents of education training in higher vocational colleges are engaged in practical work on the front line of production, construction, service, management, etc. The talent cultivation of higher vocational engineering majors mainly master the actual skills and techniques. In this paper, the course of higher vocational engineering majors is introduced, and the results of the survey results are analyzed. Such problems are found for analysis of the results: On the establishment of courses in higher vocational engineering courses, the design of curriculum system is independent, and the cultivation of students' professional quality is not sufficient, the course examination form is single, and the study link is incomplete. Through the cognitive analysis of the learning effect of vocational engineering courses, the new teaching methods have been brought forward, such as project teaching and diversity assessment etc. The cognitive analysis of the study effect of higher vocational engineering majors has an important guiding effect on the cultivation of professional talents in engineering.
\end{abstract}

\section{Introduction}

Higher vocational college education is the cultivation of senior technical talents. The talents of education training in higher vocational colleges have the necessary theoretical knowledge and strong practical ability. Higher vocational education to cultivate talents should have many characteristics, such as the strong social adaptation ability, broad knowledge, comprehensive professional skills, some creative implementation of the tasks of work ability, strong ability of application and development, positive professional attitude, etc.

Engineering is a discipline developed in combination with the technical experience accumulated in the production practice, and the engineering application is the basic science of physics, mathematics, chemistry and so on [1]. The typical disciplines include civil engineering, water conservancy, electrician, electronic information, thermal nuclear energy, instrument and instrument, chemical pharmaceutical, etc. Traditional engineering, training target is the senior engineering technical personnel on the corresponding engineering field. Engineering talent is mainly engaged in planning, exploration, design, construction and raw materials selection research and management. Engineering is the staff that must cultivate practical ability [2]. The new type of engineering is the development of the new discipline in the relevant science foundation refers to the need to adapt to the high technology development.

Higher vocational engineering majors are mainly based on mastering practical skills, which are based on certain techniques. Therefore, the establishment of course content of higher vocational engineering courses is more important to develop practical application ability [3]. Higher vocational engineering courses are based on certain business practices. Engineering majors in higher vocational colleges expect students to apply their expertise to specific work practices.

\section{Analysis of Survey Results of Engineering Majors in Higher Vocational Colleges}

The higher vocational engineering graduates are surveyed. The research subjects are engineering majors in higher vocational colleges, and these students have carried out the design of specialized course 
products [4]. Research content including these aspects, such as working task competence, professional knowledge application in the actual work situation, the theoretical knowledge and practice of the knowledge, specific recommendations for course improvements, and so on. The survey results show that the majority of students in engineering majors need half a year's fitness. The main reason for this maladjustment is that the school education is out of touch with the actual work requirements [5]. Some students pointed out that the course content of the electromechanical specialized course content is much, the class amount of specific specialized course is small, the study task is heavy. In a limited time, most teaching tasks cannot be completed. The end result is the study of the specialized courses is mixed and not refined [6]. There are obvious flaws in the order of some courses. From the level of job competence, the results show a typical normal distribution. The vast majority of graduates think they can do most of the work. Through summarizing found some problems: the design of curriculum system is independent and the cultivation of students' professional quality is inadequate, course examination form is single, and the link of learning is not perfect.

\section{Design of Course System is Independent}

Take electromechanical integrative course setting for example to carry out the following explanation. The content of the specialized courses is isolated from each other. In the course of writing the syllabus, the teaching design has not formed the integrated curriculum system. The final result shows that most teachers just teach this course knowledge alone, without effective increasing or reducing the content of the course lead to cohesive enough before and after the course, part teaching contents of repetition [7]. Most teachers report that the number of hours in specialized courses is not enough, which can not teach students to master specific knowledge. Most students report that the study pressure is great, and learning feels tired, because more courses are set.

\section{Cultivation of Students' Vocational Quality is not Sufficient}

In the course of higher vocational engineering courses, teachers and students reflect that the curriculum knowledge is piecemeal and independent, and professional skills training is single. The assessment method ignores the test of practical ability and focuses the students' attention on theoretical knowledge and local skills [8]. These defects cause students to form a complete understanding of their knowledge and skills. High vocational students lack the analytical capability and practical ability of the system. Therefore, in the process of concrete practice, it is often difficult to use these knowledge and skills to solve problems quickly and efficiently.

\section{Course Assessment Form is Single}

According to the survey results of engineering graduates of higher vocational colleges, most graduates think that the learning objectives of professional courses are only to enumerate some knowledge points. This lack of practical teaching objective makes the course study stuck in the most basic knowledge infusion stage. Such a way is not conducive to the cultivation of students' abilities. From the perspective of knowledge mastery, the understanding of knowledge is only the basic link of learning, and the flexible application is only in the text. The ultimate goal of learning is to improve your ability through research and discovery [9]. At the same time, the completion of course teaching objectives is largely based on the subjective judgment of the participants in the teaching activities and the lack of operable evaluation indexes.

At the same time, most of the students point out that the course is not properly assessed. The course assessment is carried out in the form of written test, and the test score is used to measure the students' learning effectiveness. This will lead students to focus too much on the theoretical knowledge of the course. As a result, the ability to analyze and solve problems is not strong when it comes to practical problems. 


\section{Learning Process is Incomplete}

According to the survey results of higher vocational engineering graduates, the learning process of students is incomplete and the learning habit is to be improved. The teacher pays attention to the teaching process, the student pays attention to the learning link, but the reflection of the course teaching effect and the reflection of the learning effect are missing. Courses including teachers reflection itself reflections on teaching process, teachers and teachers to study, project learning, the problems in the process of dialogue and discussion, teachers and students to study, project learning, the problems in the process of dialogue and discussion, of course, student and student project study of the problems in the process of dialogue and discussion, students to study the courses that students of learning effectiveness and efficiency of reflection, etc. During the course reflection activity, "division one", "teacher life", "life life" as the community of cooperative learning, sharing, cooperative learning and making progress together. The results show that students in engineering majors lack effective reflection in the study. From the perspective of students, the lack of effective curriculum learning reflection, not only limits the students deep understanding of knowledge, skills, flexible application, and is not conducive to students' independent innovation ability, communication ability and the ability to reflect, and ultimately affect the achievement of learning goals [10]. From the perspective of teachers, the lack of effective learning reflection also restricts the development ability of teachers' teaching materials and the improvement of teaching design ability.

In view of the above problems, the traditional teaching mode needs to be changed in the way of project teaching and micro-course teaching. Traditional teaching models need to be changed, modern teaching methods need to be added, and information technology needs to be utilized. For example, the project teaching has realized the change of teaching mode, and the diversified assessment method is more conducive to stimulating students' learning motivation.

Project course to take the student as the main body project drive, variable isolated contact before and after the course is to support each other, of course, is a single course examination mode for the diverse curriculum evaluation mode, aims to build the "comprehensive ability training as the main line, teacher as the guide, students as the main body, projects throughout" as the basic characteristics, to cultivate students' reflection learning, communication, coordination of individual and professional ability as the core target of project driving course system, training of professional knowledge and practical ability of both mechanical and electrical professional and technical personnel.

\section{Summary}

Higher vocational college education training is a senior technical talent. The talents of education training in higher vocational colleges have the necessary theoretical knowledge and strong practical ability. The talents of education training in higher vocational colleges are engaged in practical work on the front line of production, construction, service, management, etc. The talent cultivation of higher vocational engineering majors mainly master the actual skills and techniques. In this paper, the course of higher vocational engineering majors is introduced, and the results of the survey results are analyzed. Such problems are found for analysis of the results: On the establishment of courses in higher vocational engineering courses, the design of curriculum system is independent, and the cultivation of students' professional quality is not sufficient, the course examination form is single, and the study link is incomplete. Through the cognitive analysis of the learning effect of vocational engineering courses, the new teaching methods have been brought forward, such as project teaching and diversity assessment etc. The cognitive analysis of the study effect of higher vocational engineering majors has an important guiding effect on the cultivation of professional talents in engineering.

\section{Acknowledgement}

The word of this paper is supported by Teaching Reform Research Project of Xijing University (Grant No.GZJGYB1726) and Teaching Reform Research Project of Xijing University (Grant No.GZJGYB1701) . 


\section{References}

[1] Qin Zhou: Higher Vocational Education Curriculum Mode and Select. Nanjing: nanjing normal university, Vol. (2007) p.15-16.

[2] Xiangwei Liu. Based on Working Process of Development of Higher Vocational Machinery Manufacturing Professional Curriculum Strategy. Education and career, Vol. 11 (2011)p. 138-139.

[3] J.B.Wang, H.T.Yang: New Field of Overseas Investment-New Trend of Transnational Higher Education (DongYue Review, China, 2012).

[4] Mei-yun Zhang: Tumor Disease and Reform Path of Curriculum in Colleges and Universities. (Journal of China's higher education, 33-34,2010).Vol.17.

[5] Chen Lanjian: Comprehensive Vocational Ability Orientation of Higher Vocational Curriculum Reform Research. (Ph.D., Nanjing: nanjing university of science and technology, China 2008),p.20.

[6] B.C.Ji: Our Country's Higher Education Scale Forecast Analysis in 2020, Vol. 1 (2011) No. 1, p. 305.

[7] Huang Kexiao: Introduction to Vocational and Technical Education Course (Shanghai: east China normal university press, China 2000), p.136.

[8] Henry m. levin. Education How to Adapt to Future-Background of American Education, Peking University Education Review, Vol. 2 (2013), p. 2-3.

[9] Chun Zhou: Machinery Innovation Ability Structure of System Analysis of Higher Vocational Students. (School education in China, China 2011),p.56-58.

[10] Wang Boqing: 2012 Chinese University Students' Employment Report. (Beijing: social sciences academic press, China 2012),p.46. 